This is the accepted manuscript of an article published in Human Affairs, Vol. 29, No. 4, pp. 425433, October 2019. Please use the published version here for citing this article.

\title{
Beauvoir's Ethics, Meaning, and Competition
}

\section{Elena Popa}

\begin{abstract}
This paper discusses Simone de Beauvoir's views on the meaning of life as presented in The Ethics of Ambiguity. I argue that Beauvoir's view matches contemporary hybrid views on the meaning of life, incorporating both subjective and objective elements, while connecting them in a distinct way through the tension between self and other. I then analyze the meaning of excessively competitive projects through Beauvoir's ethics and conclude that success that amounts to denying other people's access to the things one values is absurd. I use the case of contemporary academia as an illustration of extreme competition, then employ Beauvoir's views to suggest a shift towards more meaningful practices.
\end{abstract}

\section{Introduction}

The problem of the meaning of life plays a central role in Simone de Beauvoir's existentialist thought. This paper analyzes Beauvoir's Ethics of Ambiguity from the perspective of current investigations on the meaning of life, particularly hybrid accounts, then employs Beauvoir's view as a framework for discussing ethical issues regarding competition. Beauvoir's requirement that in recognizing one's freedom one should respect others' agency is at odds with excessively competitive settings where success amounts to denying other people's agency and viewing them as objects. I argue that in the light of Beauvoir's considerations success in such circumstances becomes meaningless. I employ the example of present day academia to highlight when the search for knowledge can be seen as a meaningful project and when it is rendered meaningless in accordance with Beauvoir's ethics.

This investigation contributes to Beauvoir scholarship by situating Beauvoir’s work among contemporary research on the meaning of life, and by opening further connections to social philosophy. For current analytic inquiries into the meaning of life, the present paper builds further connections to the history of philosophy, and highlights an objective side to existentialist perspectives on life's meaning. 


\section{The meaning of life in The Ethics of Ambiguity}

While my argument is mainly based on The Ethics of Ambiguity, Beauvoir's earlier considerations on the importance other's people's projects and the critique of tyranny from Pyrrhus and Cineas provide a preliminary version of the argument. Upon questioning the worth of any project given its finitude, Beauvoir emphasizes the relation to other people as a way of confronting the absurd: 'so here is my situation facing others: men are free, and I am thrown into the world among these foreign freedoms. I need them because once I have surpassed my own goals, my actions will fall back upon themselves, inert and useless, if they have not been carried off toward a new future by new projects' (Beauvoir, 1944/2004, p. 135). According to Webber’s (2018) analysis of the meaning of life in Pyrrhus and Cineas, Beauvoir early ethical project can be read in Kantian key, as a categorical imperative to respect others' agency: 'Beauvoir's argument does conclude (...) that we must treat human agency as objectively valuable. This is not undermined by the fact that it will sometimes generate genuine dilemmas. Her argument also implies the further claim that we must consider this structure of human agency to be the foundation of all other values' (Webber, 2018, p. 229). On this interpretation, choices that diminish others' agency lead to absurdity, even in situations where they may be inevitable.

The relation between self and other is explored in relation to the human condition in The Ethics of Ambiguity, where Beauvoir emphasizes the tension between the freedom to determine one's nature, while simultaneously being constrained by living among other human beings: 'He asserts himself as a pure internality against which no external power can take hold, and he also experiences himself as a thing crushed by the dark weight of other things (...) This privilege, which he alone possesses, of being a sovereign and unique subject amidst a universe of objects, is what he shares with all his fellow-men. In turn an object for others, he is nothing more than an individual in the collectivity on which he depends' (Beauvoir, 1947/1976, p. 7). Departing from philosophical approaches that exclusively focus on one of these aspects while neglecting the other, Beauvoir suggests that meaning must be searched in connection to ambiguity: 'Let us try to assume our fundamental ambiguity. It is in the knowledge of the genuine conditions of our life that we must draw our strength to live and our reason for acting' (Beauvoir, 1947/1976, p. 9). Life's meaning, discussed in terms of significance, value, or transcendence, is closely connected to Beauvoir's treatment of freedom and pursuing projects: 'Freedom is the source from which all significations and all values spring' (Beauvoir, 1947/1976, p. 24).

In discussing the possibility of genuine freedom, Beauvoir relies on Sartre's claim that 'this being is the foundation of itself as a lack of being; that is, that it determines its being by means of a being which it is not' (Sartre, 1943, p. 86). Exploring how human beings succeed or fail to reach 
genuine freedom and acknowledge the ambiguity of the human condition, Beauvoir discusses several human types (and possibly historical figures). For instance, the figure of the subman reveals someone who does not acknowledge the lack of being, and, subsequently, cannot determine meaning for himself. The subman can easily succumb to tyrannical projects by the figure of the serious man. Beauvoir describes the serious man as someone who acknowledges the lack of being, but upon setting goals he takes them as absolutes, thus negating both his freedom as well as that of other people. The serious man can pursue military, economic, or political goals without ever bringing their worth into question. This way, Beauvoir holds, 'it is natural that he makes himself a tyrant. Dishonestly ignoring the subjectivity of his choice, he pretends that the unconditioned value of the object is being asserted through him; and by the same token he also ignores the value of the subjectivity and the freedom of others, to such an extent that, sacrificing them to the thing, he persuades himself that what he sacrifices is nothing' (Beauvoir, 1947/1976, p. 49). This continues Beauvoir's reflections from Pyrrhus and Cineas: a tyrant's project is bound to absurdity because it disregards the agency of the people dominated while increasing the tyrant's power.

In the Ethics of Ambiguity, tyranny is not confined to the serious man. Beauvoir explores how the adventurer (or more generally, someone pursuing one's passion) can become a tyrant, by treating other people as objects. In the same context, however, the possibility of genuine freedom is highlighted:

Passion is converted to genuine freedom only if one destines his existence to other existences through the being - whether thing or man - at which he aims, without hoping to entrap it in the destiny of the in-itself.

Thus, we see that no existence can be validly fulfilled if it is limited to itself. It appeals to the existence of others. The idea of such a dependence is frightening, and the separation and multiplicity of existants raises highly disturbing problems (Beauvoir, 1947/1976, p. 67).

Thus, one of the key differences between genuine and non-genuine approaches to freedom consists in one's relation to others. More closely connected to the question of what meaningful projects amount to, Beauvoir holds that 'no project can be defined except by its interference with other projects. To make being "be" is to communicate with others by means of being' (Beauvoir, 1947/1976, p. 71). This aspect is emphasized by Arp's analysis of Beauvoir's concept of moral freedom as 'a projection of meaning into the future by a group of intertwined freedoms' (2001, p. 72). 
Having spelled out Beauvoir's view on genuine freedom and meaningful projects, one remaining aspect relevant to the current paper is the figure of the critic. According to Beauvoir, critical thought attacks the 'serious world' while at the same time not falling into pure negation the way the adventurer or the nihilist would. Nevertheless, the critic's dedication to independence (or objective truth) is marked by ambiguity: 'the independent man is still a man with his particular situation in the world, and what he defines as objective truth is the object of his own choice' (Beauvoir, 1947/1976, pp. 68-69). A critic who does not recognize this ambiguity falls into the world of the serious man. As critical thought and dedication to the truth are central to projects pursuing knowledge, the question of how such a project is meaningful requires facing the possibility of passing from ambiguity to the serious world. In what follows I will focus on a different way in which a critic becomes a serious man: by affirming the value of his own project through denying meaningful projects to other critics.

\section{Meaningful projects and competition}

The discussion so far has emphasized Beauvoir's view on meaningful projects as recognizing ambiguity and particularly the presence of others' projects as necessary for genuine freedom. In this section I situate Beauvoir's view among contemporary analytic classifications of views on meaning in life, then explore its implications for ethical problems raised by extreme competition.

I employ Metz’s (2013a, 2013b) categorization of different views on meaning in life, particularly those falling under naturalism, describing meaning in relation to the physical world (Metz, 2013b, section 3). The subjectivist and objectivist strands of naturalism are explained by Metz as follows: subjectivism holds that 'meaning in life varies from person to person, depending on each one's variable mental states' (Metz, 2013b, section 3.1), while according to objectivism: 'meaning is constituted (at least in part) by something physical independent of the mind about which we can have correct or incorrect beliefs' (Metz, 2013b, section 3.2). These two views are not exclusive, as a meaningful life can be a matter of one's preferences while also meeting standards outside one's own perspective. This view is held, among others, by Susan Wolf: meaning 'involves subjective and objective elements, suitably and inextricably linked', or 'meaning arises when subjective attraction meets objective attractiveness' (2010, p. 9). I argue that this view also applies to Beauvoir's ethics, with significant differences from Wolf's approach.

In discussing the clash between the subjective capacity to decide meaning for oneself, and the constraints stemming from one's relation to others, Beauvoir is pointing out a tension between subjective and objective perspectives on meaning in life. Her view on the ambiguity of the human condition and genuine freedom incorporates both aspects: once one acknowledges one's freedom, 
one can pursue a project one deems meaningful; nevertheless, in so doing it is necessary to position one's projects in relation to others in certain ways. Before contrasting Beauvoir's view with Wolf's, I will address one possible objection regarding whether Beauvoir's view should be classified as hybrid given Metz's (2002; 2013b) singling out existentialism as a paradigmatic example of subjectivism about meaning in life. My analysis so far highlights a divergence between a conception of existentialism focusing on radical freedom and responsibility widely attributed to Sartre, and Beauvoir's version of existentialism. As pointed out by Simons, the relation between self and other had been a central topic in Beauvoir's work, that she addressed before Sartre: 'Beauvoir was the first one to address herself to the problem of the Other, a concern which later became so prominent in Sartre's work' (1986, p. 169). Thus, existentialism is not confined to subjective views on meaning in life, and can incorporate objective aspects as illustrated in Beauvoir's philosophy.

In an important sense Beauvoir's view fits the structure proposed by Wolf, not only in incorporating subjective and objective components, but also in capturing their interaction. Nevertheless, while Wolf proposes a view that 'sees subjective and objective elements fitting together to constitute a coherent feature a life might or might not possess' (2010, p. 20), Beauvoir emphasizes how the two are in conflict. In explaining the project of writing a novel, Wolf would refer to one's passion for writing, but also to the objective value of literature. Beauvoir's picture would add the acknowledgment of ambiguity, recognizing a possible tension between one's passion for writing, and the social conditions under which one undertakes this project. For instance, if one's living depends on it, should one write on topics one cares about or focus the interests of the public? Should one write in view of pressing social issues, or pursue a topic out of pure personal interest? We see how Beauvoir's view fits the hybrid models in a peculiar way, by capturing possible tensions and plausible dilemmas when weighing one's subjective preferences against objective conditions, among which Beauvoir particularly emphasizes social and historical factors. Beauvoir's perspective on objectivity stresses social dimensions, which need not be the case for Wolf. Consider a pioneering scientist passionate about his research making a discovery that the scientific community at the time fails to acknowledge. While on Wolf's view the discovery can be objectively valuable without social recognition, Beauvoir's perspective would identify objective meaning in how the discovery enables novel lines of research by other scientists, but not necessarily social approval per se.

The relation between meaning and morality is another point of divergence between Beauvoir and Wolf. While Wolf argues that meaning is independent from morality, in Beauvoir's work there is an important connection between the two. Wolf emphasizes how morality need not imply a 
meaningful life, as in cases where one is not interested in the particular moral projects undertaken. By contrast, Beauvoir emphasizes the absurdity of immoral projects, and the subsequent meaninglessness of an immoral life. The two views are not in conflict insofar as morality does not completely overlap with a meaningful life, but for Beauvoir morality understood as respecting others’ agency is necessary for meaning. ${ }^{1}$ Thus, while for Wolf morality is neither necessary nor sufficient for meaning in life, for Beauvoir morality is necessary for a meaningful life.

Having classified Beauvoir's view as a hybrid account on meaning in life, I will now use this framework to explore the relation between meaning and competitive projects. Wolf's view helps understand two aspects of competition: competitive projects have an objective dimension, as several people are pursuing them, and there are standards for success - say, someone who enjoys running thinks it is worthwhile to win a marathon. Now from Beauvoir's perspective, the question is whether pursuing certain kinds of competitive projects can yield a meaningful life. Competitive projects clearly evince a conflict between subject and other: in seeking victory, one may grow to view the other competitors as obstacles, and even rejoice at another competitor's misfortune if that increases one's chances of winning. To provide a satisfactory answer to this question, I will first explore ethical dimensions of competition.

Competition comes in degrees, and not all competitive settings may undermine the relation between self and other; I focus on cases where competition undermines social connectedness instead of affirming it. Hussain’s (2018) study in the context of political philosophy is illustrative of the type of competition I refer to: 'a certain degree of competition in social life is clearly acceptable, but - just as clearly - there are limits: social institutions can be morally defective when they pit people against each other excessively. (...) Excessively competitive institutions are antisocial and antithetical to certain forms of social connectedness' (Hussain, 2018, pp. 14-15). Hussain's argument holds that social connectedness would have members of a political community be 'mutually affirming with respect to the projects that constitute the common good' (p. 13). This type of political community would break down in cases of life or death competitions such as securing jobs in the context of a weak public health system; as health is part of the common good, one would end up undermining as opposed to affirming other people's benefiting from health services (pp. 1314). Thus, I will refer to competition in a qualified sense, incorporating its excessive degree and applicability to contexts where mutual affirmation is desirable.

Hussain's argument shows that excessive competition is immoral because it undermines mutual affirmation, which is seen as intrinsically valuable. Mutual affirmation, or an equivalent

1 For support of this interpretation, cf. Webber on king Pyrrhus's project being 'absurd because it is immoral' (2018, p. 231). 
concept is also present in Beauvoir's philosophy. As pointed out by Stone, for Beauvoir 'freedom is inherently opened onto other people' to the effect that 'having affirmed my native openness toward others, it would be inconsistent to then wish limits and servitude upon them' (1987, p. 125). The same point can be extended to agency and meaning - meaningful projects should not undermine social connectedness, and ideally enhance it. Insofar as extreme competition leads to denying other people the things one values, a successful project along these lines would only make sense from the perspective of the serious man and his tyrannical attitude. By contrast, Beauvoir emphasizes in Pyrrhus and Cineas: 'If I want to be courageous, skillful, and intelligent, I cannot scorn the courage, skill, or intelligence in the other' (Beauvoir, 1944/2004, p. 135). It is this particular attitude with regard to academic success that I will explore in section 4; I argue that on Beauvoir's view knowledge is more akin to the common good as opposed to a prize to be won against other competitors.

\section{Competitive critics or serious men? Meaning in present day academia}

Transferring the figure of the critic to present day, one may think of a critic seeking meaning in researching a scholarly field (say, history or literature), and by bringing forth different approaches or interpretations to challenge 'serious' stories in support of a given social or political setting. If the critic also aims to engage in teaching, she may challenge the certainties imposed on the students and encourage them to undertake critical thought on their own. In most current academic environments this project would amount to engaging in fierce competition with other academics: competing to secure short- and long-term appointments, grants and funding, publications in prestigious venues. Success in these endeavors, and thus the ability to keep on pursuing her intellectual goals, inevitably means barring other like-minded individuals from completing their meaningful projects. Further supposing the critic is successful and secures a position where she can focus on her favorite research topics, the 'two-tier' model of academic labor (see Cardozo 2017; Zheng 2018) would make this success conditional on other people working in precarious conditions in areas deemed less valuable, such as teaching, mentoring, or service. Academic success here means pursuing one’s goal while diminishing the agency of people with similar goals and values: one can dedicate one's time to research because others take over the teaching responsibilities; one can enjoy job security because other employees are on contingent appointments. Finally, in order to make her work visible and collaborate on the most successful projects, the critic may choose to primarily engage with work of academics of comparable status, disregarding people from the lower tier. Is success as portrayed in this scenario something that the critic would hope for, or has the critic become the serious man? 
As discussed in section 2, the goals of the critic appear meaningful in Beauvoir's analysis as long as they challenge the serious world and the critic is aware of the ambiguity of human existence. Once such projects are possible only in a hyper competitive setting, as is the case today, they are presented as worthy of sacrificing other people's freedom and agency - by simply securing the benefits of academia in the first instance, but also by keeping other people in precarious conditions. This picture of academia looks very similar to the world of the serious man, or the tyrant.

It may be objected that this need not always be the case about academia, since not all successful academics look down upon less acclaimed peers. Even so, kindness to fellow academics does not rule out the allegiance to the 'serious world' and absolute goals. To fulfill Beauvoir's conditions for meaning, one would need to act to render co-existing projects possible.

Another objection would point to the benefits of competition: many academics find debates stimulating. This objection, however, relies on a sense of competition different from the one discussed above: academics who end up improving their work as a result of fierce debates are arguably affirming one another's passion for the subject. If anything, the winner would lose from having a rival driven out of the profession, which further emphasizes the absurdity of victory in competitions where one either wins or perishes.

Yet another objection would hold that Beauvoir's considerations might as well apply to all competition, as examples such as professional sport show. Without analyzing competition in sport, in response I distinguish success from agency. Winning a contest means everyone else loses, but that does not necessarily rule out acknowledging the top performers, or diminish their capacity to compete again. In fact, the existence of the practice is conditional on the availability of competitors. By contrast, success at securing a 'first tier' academic position renders other academics less capable of pursuing their projects as they would do so with diminished access to time for research or other resources. Also, it is difficult to see how the existence of academic work would depend on this particular structure. The former illustrates success at the expense of others' success characteristic of all competitive projects, but it is the latter - success at the expense of others' agency - that counts as absurd on Beauvoir's account.

Success according to current academic measurements appears, thus, absurd because it undermines others' agency. This also transpires from sociological analyses of academic competition, as Carson et al. note: 'What prevents us from opening our eyes to the absurdity of the academic situation? (...) Coming back to Alice’s question “Who won the race?” we conclude that currently we are all losing' (2013, p. 189). While Beauvoir's view helps explain why this way of pursuing knowledge is unethical and therefore meaningless, it can also point possible shifts in focus 
to render it meaningful. One possibility would be to emphasize the inherent value of knowledge as opposed to the benefits of an academic position. However, Beauvoir would classify this attitude as inauthentic because it lacks a direct connection to agency (Shabot 2016). ${ }^{2}$ Since agency is central to realizing one's freedom according to Beauvoir, a purely contemplative stance (say, intellectual or aesthetic) takes the world for granted and denies one’s agency (Beauvoir 1947/1976, pp. 35-37). Furthermore, and more closely related to the purposes here, pursuing a project for its own sake does not necessarily involve social connectedness, as it can be done in isolation from other people's projects.

Another way to go, that, I argue, can be derived from Beauvoir's view, investigates knowledge through the perspective of the relation between self and other. Relevant questions arising here would concern how one can use knowledge to increase others' agency and possibilities of pursuing meaningful projects. Another look at academia shows that teaching, mentoring, or collaborative endeavors are ways of valuing other people's projects and increasing their agency. An academic introducing students to a research topic enables them to pursue epistemic goals and possibly affirm freedom against the serious world. As Bergoffen describes Beauvoir's views, 'the success of our projects depends on the extent to which they are adopted by others' (2018, section 2). Under this standard, it is unclear how academic projects can be meaningfully continued when academics compete to secure resources in an environment where secure positions are disappearing. By contrast, introducing others to the topic one deems valuable emphasizes its worth and enables its continuation in one form or another.

To conclude, analyzing academic projects through Beauvoir's considerations on meaning in life shows why practices that disregard other people are ultimately meaningless, while increasingly neglected parts of the academic life, such as teaching, justify the meaning of one's pursuit of knowledge.

\section{Conclusions}

This paper has explored how Beauvoir's existentialist ethics contributes to current debates on meaning in life. Notably, Beauvoir's account of the relation between self and other and the ambiguity of human existence raises important questions regarding the meaning of competitive projects. I have shown how Beauvoir's approach can be employed to understand meaning in relation to other people, and to criticize antisocial pursuits or institutions in view of their meaninglessness. More broadly, the present investigation shows how philosophical research on the meaning of life, and Beauvoir's view in particular, can provide leads to understanding the

2 Also see Shabot (2016) for a critique of this view. 
importance of social connectedness in seeking meaning. The analysis of academia from an existentialist perspective explains its absurd aspects while also showing the need for a shift in focus, towards more mutually affirming practices. Thus, the importance of Beauvoir's philosophy with respect to meaning in life goes beyond understanding concepts, assisting in making sense of broader social situations.

\section{References}

Arp, K. (2001). The bonds of freedom: Simone de Beauvoir's existentialist ethics. Open Court Publishing.

Beauvoir, S. (1947/1976). The Ethics of Ambiguity. Trans. B. Frechtman. New York: Citadel Press. Beauvoir, S. (1944/2004). Pyrrhus and Cineas. In M. A. Simons, M. Timmerman, and M. B. Mader (eds.), Philosophical Writings (pp. 89-149). Urbana: University of Illinois Press.

Bergoffen, D. (2018). Simone de Beauvoir, In E.N. Zalta (ed.), In The Stanford Encyclopedia of Philosophy (Fall 2018 Edition), URL =

<https://plato.stanford.edu/archives/fall2018/entries/beauvoir/>.

Cardozo, K. (2017). Academic labor: Who cares?. Critical Sociology 43 (3), 405-28.

Carson, L., Bartneck, C., \& Voges, K. (2013). Over-competitiveness in academia: a literature review. Disruptive science and technology, 1(4), 183-190.

Hussain, W. (2018). Why should we care about competition?. Critical Review of International Social and Political Philosophy, 21(5), 570-585.

Metz, T. (2002). Recent work on the meaning of life. Ethics, 112(4), 781-814.

Metz, T. (2013a). Meaning in Life: An Analytic Study. Oxford: Oxford University Press.

Metz, T. (2013b). The Meaning of Life. In E.N. Zalta (ed.), The Stanford Encyclopedia of

Philosophy (Fall 2018 Edition), URL = < https://plato.stanford.edu/archives/sum2013/entries/lifemeaning/>.

Sartre, J.P. (1943/1978). Being and Nothingness: An essay on phenomenological ontology. Trans. Hazel E. Barnes. Pocket Books.

Simons, M. A. (1986). Beauvoir and Sartre: The philosophical relationship. Yale French Studies, (72), 165-179.

Shabot, S. C. (2016). How free is Beauvoir's freedom? Unchaining Beauvoir through the erotic body. Feminist Theory, 17(3), 269-284.

Stone, B. (1987). Simone de Beauvoir and the existential basis of socialism. Social Text, (17), 123133. 
Webber, J. (2018). Beauvoir and the meaning of life. In S. Leach, J. Tartaglia (eds.), The Meaning of Life and the Great Philosophers (pp. 224-231), Routledge.

Wolf, S. (2010). Meaning in life and why it matters. Princeton University Press.

Zheng, R. (2018). Precarity is a Feminist Issue: Gender and Contingent Labor in the Academy. Hypatia, 33(2), 235-255. 